\title{
Perception of clicks in music
}

\author{
ANDREW H. GREGORY \\ University of Manchester, Manchester M13 SPL, England
}

\begin{abstract}
Subjects were asked to judge the position of a click that occurred during a short piece of music. Clicks were, on average, judged to be later than their actual position. The click and the music were presented through headphones to different ears, and the clicks were judged to be significantly later if they arrived at the right ear rather than at the left. There was also a significant tendency for clicks to be attracted to phrase boundaries in the music. These last two results are similar to those from experiments with a click during speech, but the late judgments of a click in music contrast with the early judgments of a click in speech.
\end{abstract}

There are several interesting analogies between the perception of music and the perception of language. In particular, the grouping of items into phrases is an important principle for both. Sloboda (1977) has studied the eye-hand span of musicians sight-reading music from a projected slide by occluding the slide, and found that they tended to continue playing up to a phrase boundary. This is analogous to the experiment by Levin and Kaplan (1970) on eye-voice span for subjects reading prose, who tended to continue reading to a phrase boundary when the text was removed. Similarly, Sloboda (1976) found that errors in both musical and verbal texts were least likely to be detected near the middle of words or musical phrases.

One well-known perceptual effect related to linguistic phrases is the demonstration by Fodor and Bever (1965) that the apparent location of a click presented during a spoken sentence tends to be displaced towards a phrase boundary or syntactic break. Reber and Anderson (1970) confirmed this effect when the sentence was read with normal intonation, but not in a monotone, thus emphasizing the linguistic nature of the effect. They, and Reber (1973), also used a control group, who were asked to guess the position of nonexistent clicks, and found that a high proportion of these responses also occurred at syntactic breaks. They suggested that the effect was at least partly due to response bias, but one can argue that even this response bias demonstrates the psychological reality of linguistic segments.

Another effect found by Fodor and Bever (1965) is that if the click and the sentence are presented through headphones to different ears, the click tends to be judged earlier when it arrives at the left ear and the sentence to the right than for the opposite condition. This has been confirmed by Bertelson and Tisseyre (1972), who found that clicks were, on average, perceived 1 syllable early $(0.14 \mathrm{sec})$ if they came to the left ear, with the sentence to the right, and about 0.6 syllable early $(0.09 \mathrm{sec})$ if they came to the right ear.

There is also a general tendency to judge the click as earlier than its actual position. Ladefoged and Broadbent (1960), in the original paper on the phenomenon, found that, on average, the click was reported 1 syllable early when the click and the sentence came through loudspeakers. Bertelson and Tisseyre (1970), also using loudspeakers, found that the click was perceived about 1 syllable early if there was no prior knowledge of the sentence, and 0.3 syllable early if there was prior knowledge. However, Bertelson and Tisseyre (1975) also found that if subjects had no warning that a click was to be presented, the click was perceived as late if it was presented from a loudspeaker to the right of the subject and the speech from the left.

If the perception of music is basically similar to that of speech, then one would expect the apparent position of a click presented during music to vary in a similar manner to that of a click during speech. However, the ear asymmetry effect may be related to cerebral dominance for language, and its direction for a click in music would then depend upon which cerebral hemisphere mediates the perception of music.

The evidence concerning hemispheric dominance and the perception of melodic sequences is not conclusive, and has recently been well reviewed in chapters by Benton (1977), Damásio, and Damásio (1977), and Wyke (1977). Neurological evidence shows that receptive amusia may exist with or without aphasia, and may result from left- or right-sided temporal lesions. Milner (1962) found that tonal memory and some other musical abilities were impaired by excision of the right temporal lobe, but not the left. Gordon (1974) mentions two cases of hemispherectomy, in one of which the removal of the right hemisphere left speech unimpaired but caused severe deficits in musical abilities, "while in the other, removal of the left hemisphere impaired speech but had little effect upon musical abilities.

Psychological evidence comes mainly from dichotic listening studies, where superior performance by one ear is assumed to reflect mediation by the contralateral hemisphere, Kimura (1964) found a left-ear superiority for recognizing dichotic melodies, as opposed to a right 
ear superiority for dichotic digits. However, Gordon (1970), using musically experienced subjects, found no significant difference between the ears for dichotic melodies, although there was a left-ear dominance for recognizing dichotic chords. Bever and Chiarello (1974), on a monaural listening task, found that musically experienced subjects were more accurate with the right ear, and nonmusical subjects better with the left ear.

One possible explanation of these results is that musical subjects may tend to recognize the whole tune, while nonmusical subjects may rely more on recognizing individual notes, and that these two tasks may be mediated by the left and right hemisphere, respectively. This would agree with the general idea (Efron, 1963) that the left hemisphere is specialized for temporal tasks, whether linguistic or nonlinguistic. This has been supported by Halperin, Nachshon, and Carmon (1973), who found a right-ear dominance for recognizing dichotic three-tone sequences with two transitions, and by Papçun, Krashen, Terbeek, Remington, and Harshman (1974), who found a right-ear dominance for trained Morse operators recognizing dichotic Morse code signals. This idea would predict that the ear asymmetry effect for a click in music would be in the same direction as for a click in speech, that is, the click would be judged earlier when it arrived in the left ear than when it arrived in the right.

\section{METHOD}

One problem with experiments on music perception is that the majority of people are not well trained at sight-reading music. It was decided for this initial study to use subjects unselected for musical ability and to use the same short tune on each trial. The subjects were shown the musical notation for a short tune consisting of six notes of equal duration, and even nonmusical subjects were confident at indicating the position of the click. Figure 1 shows one of the tunes used. In order to study the effects of phrase boundaries, half the subjects were told to think of the tune as two triplets and were shown the notation in Figure 1a, while the others were told to think of three pairs of notes and were shown the notation in Figure $1 b$.
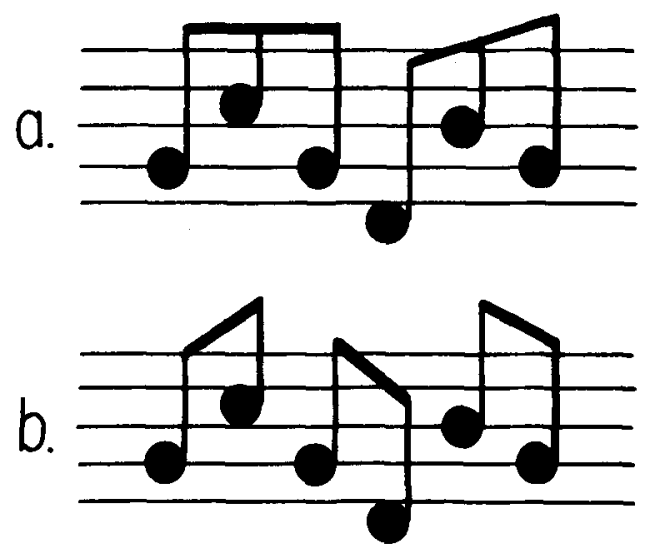

Figure 1. The two modes of visual presentation for one of the tunes used.
It was thus predicted that clicks on the third and fourth notes would be heard in the intervening pause in the first case and in the earlier or later pauses in the second case. This method has the advantage that the phrase boundary is entirely perceptual and does not coincide with a long acoustic pause.

\section{Stimuli}

Each stimulus consisted of a six-note tune delivered to one ear and a click to the other ear. The tunes consisted of a set of pure tones generated by a Modular One computer connected to a Leak stereo amplifier through a DAC synchronized to an external crystal oscillator. The frequencies of the notes were those of the natural scale $(A=440 \mathrm{~Hz})$. Three different tunes were used: (1) G, C, G, D, B, G; (2) B, F, C, G, D, C; and (3) F, G, D, B, F, C. $(D=297 \mathrm{~Hz}, F=352 \mathrm{~Hz}, \mathrm{G}=396 \mathrm{~Hz}$, $\mathrm{B}=495 \mathrm{~Hz}, \mathrm{C}=528 \mathrm{~Hz}$ ).

The tunes were presented at two speeds. At the slow rate, the duration of each note was $200 \mathrm{msec}$ and at the fast rate $100 \mathrm{msec}$. The notes were separated by pauses of the same duration as the notes themselves. Each note had a rise and fall time of about $10 \mathrm{msec}$, and all were of equal amplitude. The clicks were produced by a square wave of $0.1 \mathrm{msec}$ duration, on the opposite channel from the tune, and were positioned precisely in the middle of either a note or a pause.

For each of the three tunes, a tape was prepared comprising 2 slow practice trials, with the duration of notes and pauses being $400 \mathrm{msec}$, then 18 slow trials followed by 18 fast trials. Each tune was followed by a 7-sec pause and preceded by a 200 -msec warning tone (G) on both channels $2 \mathrm{sec}$ before the tune.

Each block of 18 trials included 9 with the tune to the left ear and 9 to the right, in randomized order. Clicks, on the opposite ear, were positioned at the center of the $2 \mathrm{nd}, 3 \mathrm{rd}, 4$ th, or 5 th note or the pauses in between them. There were two clicks at each of these seven positions, except the 3rd and 4th notes, which had four clicks in order to increase the accuracy of analysis of phrase boundary effects. The order of these click positions was randomized in each block of 18 trials.

The tape was played on a Sony TC-377 tape recorder, using TDH-39 headphones matched to $\pm 2 \mathrm{~dB}$. The intensity of the tones was $80 \mathrm{~dB}$ SPL, measured with an artificial ear (Brüel \& Kjaer Type 4152) and a sound-level meter (Brüel \& Kjaer Type 2203). The click was examined on an oscilloscope connected to the output of the sound-level meter, and was found to be a biphasic spike of $1.5 \mathrm{msec}$ duration, with approximately equal amplitude excursions in both positive and negative directions. The peak-to-peak amplitude was five times that of the tone measured in the same way.

\section{Procedure}

Thirty-six young right-handed adult subjects with normal hearing participated in the experiment. Each tune was heard by 12 subjects, for half of whom the headphones were reversed. For each of these six groups of subjects, half were told to think of the tune as two triplets and half as three pairs of notes. The subjects were asked to point to the note or the pause between notes where they thought the click had occurred.

\section{RESULTS}

Each response was scored according to the number of intervals (notes and pauses) after the stimulus. Thus, a click during the third note would be scored as +2 if it was reported on the fourth note, and as -1 if on the pause before the third note.

Table 1 shows the numbers of early, equal, and late responses, and the mean apparent delay of the click converted to milliseconds. The results are summed over 
Table 1

\begin{tabular}{lcccc}
\hline & Early & Equal & Late & Delay* \\
\hline Click-R & 106 & 306 & 236 & 43 \\
Click-L & 143 & 320 & 185 & 17 \\
Combined & 249 & 626 & 421 & 30 \\
\hline
\end{tabular}

*Mean apparent delay in milliseconds.

Table 2

Frequency of Responses to Clicks on the Third and Fourth Notes that Fall in Central or Outer Pauses

\begin{tabular}{ccc}
\hline $\begin{array}{c}\text { Perceived } \\
\text { Pattern }\end{array}$ & $\begin{array}{c}\text { Central } \\
\text { Pause }\end{array}$ & $\begin{array}{c}\text { Outer } \\
\text { Pauses }\end{array}$ \\
\hline $2 \times 3$ Notes & 78 & 57 \\
$3 \times 2$ Notes & 59 & 76 \\
\hline
\end{tabular}

all stimuli for all subjects and are analyzed for ear of presentation. $^{1}$

Overall, late responses are much more frequent than early ones, and this difference is highly significant on a binomial test $(z=6.7, p<.001)$.

The mean subjective delay of the click was $30 \mathrm{msec}$. There was no significant difference between the results of 20 of the subjects who had received some training at reading music and those of the 16 subjects who had had no musical training.

There were more late and fewer early responses when the click was presented to the right ear and the tune to the left than in the reverse condition.

This asymmetry between the ears is significant $\left(\chi^{2}=10.85, p<.001\right)$. The mean apparent delay with the click to the right ear was $43 \mathrm{msec}$ and with the click to the left ear, $17 \mathrm{msec}$.

To study the effect of phrase boundaries, responses to all the clicks occurring during the third and fourth notes were examined. Only the responses in a pause adjacent to the note on which the click occurred were analyzed. Responses were classified as being in the central pause, between the third and fourth notes, or in one of the two outer pauses, either before the third note or after the fourth. The central pause corresponds to a phrase boundary when the notes are perceived in two groups of three, while the outer pauses are both phrase boundaries when the notes are perceived in three groups of two. Table 2 shows the result of this analysis for relevant responses from the 18 subjects under each condition.

For both perceptual conditions, responses are more frequent at the phrase boundaries, and this is a significant tendency $\left(\chi^{2}=4.8, \mathrm{p}<.05\right)$.

\section{DISCUSSION}

Clicks do not seem to be attracted towards phrase boundaries, suggesting that the perception of music, as of speech, is organized into phrases. This effect, although significant, is not very marked, but this may be partly due to the fact that not all subjects perceived the phrases in the way suggested by the experimenter.

The most interesting result is that the click is, on average, perceived later than its actual time of occurrence, whereas with speech it is usually perceived earlier.

Ladefoged and Broadbent (1960) invoked Titchener's (1909) law of prior entry: "The stimulus for which we are predisposed requires less time than a like stimulus, for which we are unprepared, to produce its full conscious effect." However, on this principle, listeners would surely be predisposed towards (or attending to) the stimulus which commences first, that is, the sentence or the music, and it is the click which should be delayed. The principle thus does not support the early perception of a click in speech, but does support the late perception of a click in music. It may well be that there are special linguistic processes which produce a delay in speech perception relative to nonlinguistic stimuli.

The ear asymmetry effect appears to be in the same direction for both music and speech. Clicks tend to be perceived earlier if they arrive at the left ear, with the speech or music at the right ear, than for the opposite condition. If the ear asymmetry effect reflects cerebral dominance, then this would agree with the idea that temporal judgments are mediated by the left cerebral hemisphere for both linguistic and nonlinguistic situations.

The experiment is clearly worth repeating with musically trained subjects sight-reading longer passages of genuine music, as this would be more analogous to the linguistic experiments.

\section{REFERENCES}

Benton, A, L. The amusias. In M. Critchley \& R. A. Henson (Eds.), Music and the brain. London: Heinemann, 1977.

Bertelson, P., \& Tisseyre, F. Perceiving the sequence of speech and non-speech stimuli. Quarterly Journal of Experimental Psychology. 1970, 22, 653-662.

Bertelson, P.. \& Tisseyre, F. Lateral asymmetry in the perceived sequence of speech and nonspeech stimuli. Perception \& Psychophysics, 1972, 11, 356-362.

Bertelson, P., \& Tisseyre, F. Set and lateral asymmetry in the perceived sequence of speech and nonspeech. In P. M. A. Rabbitt \& S. Dornic (Eds.), Attention and performance $V$. London: Academic Press, 1975. Pp. 11-19.

Bever, T. G., \& Chiarello, R. J. Cerebral dominance in musicians and nonmusicians. Science, 1974, 185, 537-539.

Damásio, A. R., \& Damásio, H. Musical faculty and cerebral dominance. In M. Critchley \& R. A. Henson (Eds.), Music and the brain. London: Heinemann, 1977. Pp. 141-155. '

EFRON, R. The effect of handedness on the perception of simultaneity and temporal order. Brain, 1963, 86, 261-284.

Fodor, J. A.. \& Bever, T. G. The psychological reality of linguistic segments. Journal of Verbal Learning \& Verbal Behavior. 1965, 4. 414-420.

GoRDON. H. W. Hemispheric asymmetries in the perception of musical chords. Cortex, 1970, 6, 387-398.

Gorbon, H. W. Auditory specialization of the right and left hemispheres. In M. Kinsbourne \& W. L. Smith (Eds.), 
Hemispheric disconnection and cerebral function. Springfield, I11: Thomas, 1974.

Halperin, Y., Nachshon, I., \& Carmon, A. Shift of ear superiority in dichotic listening to temporally patterned nonverbal stimuli. Joumal of the Acoustical Society of America, 1973, 53, 46-49.

KimURA, D. Left-right differences in the perception of melodies. Quarterly Journal of Experimental Psychology, 1964, 16, 355-358.

Ladefoged, P., \& Broadbent, D. E. Perception of sequence in auditory events. Quarterly Joumal of Experimental Psychology, $1960,12,162-170$.

LeVin, H., \& KaplaN, E. A. Grammatical structure and reading. In $\mathrm{H}$. Levin \& J. P. Williams (Eds.), Basic studies on reading. New York: Basic Books, 1970. Pp. 119-133.

MILner. B. Laterality effects in audition. In V. B. Mountcastle (Ed.), Interhemispheric relations and cerebral dominance. Baltimore: Johns Hopkins Press, 1962. Pp. 177-195.

Papçun, G.. Krashen, S., Terbeek, D., Remington, R., \& HARSHMAN, R. Is the left hemisphere specialized for speech, language and/or something else? Journal of the Acoustical Society of America, 1974, 55, 319-327.

REBER, A. S. Locating clicks in sentences: Left, center and right. Perception \& Psychophysics. 1973, 13, 133-138.
Reber, A. S., \& ANoErson, J. R. The perception of clicks in linguistic and nonlinguistic messages. Perception \& Psychophysics, 1970, 8, 81-89.

Sloboda, J. A. The effect of item position on the likelihood of identification by inference in prose reading and music reading. Canadian Journal of Psychology, 1976, 30, 228-237.

SLOBoda, J. A. Phrase units as determinants of visual processing in music reading. British Journal of Psychology, 1977, 68, 117-124.

TITChENER, E. B. Lectures on the experimental psychology of the thought processes. New York: Macmillan, 1909.

WyKe, M. A. Musical ability: A neuropsychological interpretation. In M. Critchley \& R. A. Henson (Eds.), Music and the brain. London: Heinemann, 1977. Pp. 156-173.

\section{NOTE}

1. The results for the two speeds of tune were combined, since any difference between them could not be separated from order effects.

(Received for publication August 8, 1977; revision accepted May 9,1978 .) 